\title{
Evaluation Preliminary of a Dry Emulsion System as a Pasteurella multocida Oral Carrier for Pigs
}

\author{
David Quintanar-Guerrero', Edgar Aguilera Cerón¹, María Elena Trujillo Ortega², \\ Sofia González Gallardo', Alejandro Vargas Sánchez², Abel Ciprián Carrasco', \\ Susana Mendoza Elvira ${ }^{{ }^{*}}$
}

${ }^{1}$ Facultad de Estudios Superiores Cuautitlán, Universidad Nacional Autónoma de México, Mexico City, México ${ }^{2}$ Facultad de Medicina Veterinaria y Zootecnia, Universidad Nacional Autónoma de México, Mexico City, México Email:*seme@unam.mx

How to cite this paper: Quintanar-Guerrero, D., Aguilera Cerón, E., Trujillo Ortega, M.E., González Gallardo, S., Vargas Sánchez, A., Ciprián Carrasco, A. and Mendoza Elvira, S. (2020) Evaluation Preliminary of a Dry Emulsion System as a Pasteurella multocida Oral Carrier for Pigs. Journal of Biosciences and Medicines, 8, 114-124.

https://doi.org/10.4236/jbm.2020.89009

Received: July 23, 2020

Accepted: September 11, 2020

Published: September 14, 2020

Copyright $\odot 2020$ by author(s) and Scientific Research Publishing Inc. This work is licensed under the Creative Commons Attribution International License (CC BY 4.0).

http://creativecommons.org/licenses/by/4.0/

\begin{abstract}
Background: This work evaluated the capacity of a dry emulsion as a carrier of viable microorganisms with potential use as prophylaxis of infectious diseases. Methods: The aqueous phase containing $P$. multocida not viable in PBS was emulsified in mineral oil to obtain a w/o emulsion. The microorganisms remained stable and only in two cases $(n=6)$ did the bacterial concentration decrease. Scanning Electron Microscopy (SEM) revealed a structure of a system with the organized association of particles with cubic symmetry. Using two ex vivo bioadhesion systems, it was demonstrated that the disperse-adsorbed system is capable of adhering to the intestinal mucosa and remains adhered for long periods of time. Results: The no viability of the bacteria in the dry emulsion and the possibility of controlled release were confirmed. In vivo trial was conducted in pigs. It was possible to locate the emulsion and the bacteria attached to the gut of the living animal. An ELISA kit was used to monitor the mean antibody titer of treated pigs over a 2-week period, and a classic primary response curve occurred when the titer was plotted against time. Conclusion: We propose the disperse-adsorbed system as an alternative to commonly used vehicles for immunogens in the oral vaccines.
\end{abstract}

\section{Keywords}

Dry Emulsion, Oral Carrier, Pasteurella multocida, Pigs, Bioadhesion

\section{Introduction}

Many pathogens gain entry into their host via mucosal surfaces; therefore, en- 
hancing immunity at mucosal sites, particularly those that act as a portal of microbial entry, appears to be the most rational objective for implementing a mucosal immunization regime [1] [2]. Atrophic rhinitis due to Pasteurella multoci$d a$ is a major problem in swine production because it causes weight loss in growing pigs, increasing days to market and included productions [3] [4]. Pneumonia due to Pasteurella multocida is a secondary pathogen that is generally associated with a primary bacterial infection or an infection due to $M$. hyopneumoniae or several viral infections such as Aujeszky disease and classical swine fever [5] [6] [7]. Some studies focus on oral administration of vaccines since 1) the oral route appears to be easy to achieve in animal handling; and 2) the gut-associated lymphoid tissues (GALT) represent the largest mucosal area, and it is characterized by lymphoid follicles named Peyer's patch (PPs) [8]. In pigs, PPs are the major organized lymphoid structures involved in the induction of mucosal immune responses in the gut. While the porcine jejunal PPs represent a $\mathrm{T}$ cell compartment and a secondary lymphoid organ, the pig ileal is a primary lymphoid organ generating $\mathrm{B}$ lymphocytes. Activated $\mathrm{T}$ and $\mathrm{B}$ cells migrate from the PPs through the mesenteric lymph nodes and via the thoracic duct into the system circulation, subsequently migrating to the intestinal lamina propria [9] [10] [11]. Control of mucosal infections through vaccination requires immunization strategies that encourage the production of secretory antibodies and appropriate regulatory $\mathrm{T}$ cells to enhance mucosal immunity. Although the oral route of immunization has been recognized as capable of inducing mucosal antibody response, in practice, it is usually ineffective. This is probably due to antigen degradation by gastric acids and proteolytic enzymes both in the intestinal and gastric lumen as well as by absorption into intestinal lamina propria [9] [10] [11].

To prevent animal diseases, an opportune and effective vaccination treatment or program should be used to reduce economic losses, increase productivity and ensure high-quality products for the customer. To overcome these problems, several innovative strategies utilizing new drug delivery systems and carriers have been proposed [12] [13] [14]. Additionally, bioadhesive systems or genuine nanomaterials are preferred due to their capacity to adhere or to infiltrate into the mucosae.

The purpose of this study was to evaluate the bacterium viability in a proposed formulation based on a dry emulsion The ex vivo bioadhesion to the gastrointestinal tract of the formulation and the bacterial in vitro release profile and the serological response were determined to probe the emulsion functionality as a biological protective and immunizing oral carrier.

\section{Materials and Methods}

\subsection{Bacterial Strain}

Pasteurella multocida strain was obtained from the lungs of pigs showing clinical pneumonia. Samples were cultured on brain-heart infusion agar (Difco Labora- 
tories, Detroit, MI, USA) and incubated aerobically overnight at $37^{\circ} \mathrm{C}$. Pasteurella multocida type A was identified by standard procedures [15] [16]. The biomass was inactive with formaldehyde $0.5 \%$ for 12 hours by washing the plates with PBS, and the bacterial concentration was standardized spectrophotometrically $(660 \mathrm{~nm})$ at $10^{8} \mathrm{CFU} / \mathrm{ml}$. To obtain optimal growth conditions, the bacterial suspension (5\%) was inoculated into flasks with $50 \mathrm{ml}$ brain-heart infusion broth with three different $\mathrm{pH}$ values $\left(6.0,6.5\right.$ and 8.0) and incubated at $37^{\circ} \mathrm{C}$ for $18 \mathrm{~h}$ with constant shaking at $50 \mathrm{rpm}$., at the same time dilutions are made of this sample and plated on agar, so the count of each dilution is made and the $\mathrm{CFU} / \mathrm{ml}$ is obtained, it was repeated 3 times. The bacterial concentration in units of colony forming units per milliliter $(\mathrm{CFU} / \mathrm{ml})$ was determined at different times.

\subsection{Disperse-Adsorbed System}

Pasteurella multocida was prepared using the traditional method of emulsification but without incorporating stabilizers [17]. The first step was to prepare a primary w/o emulsion by homogenizing the aqueous phase (bacteria inactivated in PBS) in the oil phase (mineral oil USP/NF 55, Cosmopolita S. A. de C.V. México) with vigorous propeller stirring (1500 rpm Caframo R2R2-64 Ontario, Canada) at $37^{\circ} \mathrm{C}$. Then, the w/o emulsion was blended with hydrophilic silica (Aerosil $^{\circledR}$ 200, Degussa, W. Germany) to obtain a turbid liquid. Finally, hydrophobic silica (Aerosil ${ }^{\circledR}$ R972) was added, and a viscous fluid powder (dry emulsion) was obtained. One gram of hydrophilic silica for each $5.7 \mathrm{ml}$ of aqueous medium and $1 \mathrm{~g}$ of hydrophobic silica for each $3 \mathrm{ml}$ of oil medium were used. Twelve batches were prepared for the study. The distribution of bacteria in the system was determined by light microscopy and scanning electron microscopy (SEM). Pasteurella multocida viability was evaluated after preparation by determining the number of CFU/ml. To detect the presence of the dry emulsion in the in vivo test on mucosa, a marker consisting of $300 \mu \mathrm{l}$ of colloidal silver flakes obtained from an electroconductive silver adhesive (SPI, high purity silver paint) was dispersed in the final product. The flakes were selected as markers due to their morphology and their ability to emit secondary electrons.

The bioadhesive properties of the dry emulsion were evaluated using an in situ method as proposed by Rao and Buri [18]. Briefly, longitudinal sections (30 $\mathrm{cm}$ long) from the duodenum, jejunum or ileum were removed from commercial Yorkshire pigs at the slaughterhouse immediately after death and were quickly transported to the laboratory in $0.9 \%$ saline solution. The intestine samples were clipped to a cylindrical transversal section of a polyvinyl chloride tube (diameter $=10 \mathrm{~cm}$ ) and fixed in a platform at a $45^{\circ}$ angle. The intestine sections were washed with Sorensen buffer ( $\mathrm{pH}$ 6.0) using a peristaltic pump with a flow rate of $25 \mathrm{ml} / \mathrm{min}$ for $30 \mathrm{~min}$. Then, $100 \mathrm{mg}$ of dry emulsion was homogenously distributed on the tissue sections, allowing interaction of the powder with the mucosa for $10 \mathrm{~min}$. Afterwards, the system was eluted with simulated intestinal 
medium at a flow rate of $25 \mathrm{ml} / \mathrm{min}$ for 60 minutes. During the entire process, the fluid covered the tissue area to determine the persistence of the dry emulsion or bacteria on the mucosa. Different mucosa sections were taken after treatment and examined with light microscopy and scanning electron microscopy.

The determination of adhesion strength to intestinal pig mucosa was evaluated following a previously described method using a modified Du Noüy tensiometer [13] [19]. The ring was replaced by a square metallic plate $\left(4.00 \mathrm{~cm}^{2}\right)$, and the original filament was replaced by a stainless-steel filament similar to piano strings of 0.22 gauge. The device was calibrated using reference weights and validated for this kind of measurement, the calibration and validation were performed following manufacturer instructions. Each section of mucosa was placed on the plate with the mucous surface exposed $\left(3 \mathrm{~cm}^{2}\right)$ and fastened by a plastic holder and 4 staples. A dry emulsion sample was attached to the tensiometer platform. It was allowed to be in contact with the membrane for $30 \mathrm{~s}$, thus causing the dial to spin at a constant rate. The adhesion force reading is obtained when the gel disk is detached from the mucosa. Evaluations were made in triplicate. The in vitro dissolution assay was performed by using the USP 24 apparatus II (paddles) using $250 \mathrm{ml}$ of simulated intestinal fluid at $37^{\circ} \mathrm{C}$ and a stirring rate of $50 \mathrm{rpm}$. One gram of the disperse-adsorbed system was placed between filter paper (diameter of $2.5 \mathrm{~cm}$ ) and mesh (U. S. Standard 60, $250 \mu \mathrm{m}$ pore), and this system was immersed in the dissolution medium. Samples were taken at different intervals between 0 and 120 hours, and the bacteria released were correlated to the $\mathrm{CFU} / \mathrm{g}$.

\subsection{Experimental Design}

Nine intact male Yorkshire weanling pigs (7 weeks old) were obtained from an animal house. The animals were kept in isolation units and fed standard pig feed and water ad libitum throughout the study. All experiments were conducted in compliance with the Mexican Regulations for Animal Care and Maintenance (NOM-062-200-1999). The pigs were randomly divided into three groups $(\mathrm{n}=$ 3): group A, control animals (untreated); group B, treated with the dry emulsion containing the marker at $0.5 \mathrm{ml}$; and group $\mathrm{C}$, pigs treated once with a dry emulsion of Pasteurella multocida $10^{8} \mathrm{CFU} / \mathrm{g}$. The pigs were fed for fifteen days. Serum samples were collected weekly over 2 weeks (1, 7 and 15 days), and pig antibody responses were monitored using ELISA [20] [21].

\subsection{Scanning Electron Microscopy (SEM)}

The pigs were euthanized (NOM-062-200-1999), necropsied and small fractions of duodenum, jejunum and ileum were collected for evaluation. The samples were fixed by perfusion with Karnovsky's fixative containing $1 \%$ tannic acid [22] and were then dehydrated in absolute alcohol, dried at critical point in a Tousimis sample dryer (Samdri-780A, Tousimis Research Corporation, Rockville, USA) and gold coated in a Finecoat Ion Sputter (JFC-1100, JEOL LTD, Tokyo, 
Japan). Samples were then examined using a scanning electron microscope (JEOL JSM/25 S II. Tokyo, Japan). For the in vivo study, a low vacuum (SEM JEOL JSM5410LV) was used since the ion sputter device could not produce a continuous electroconductive coat to avoid charging.

\subsection{Serology}

The pig antibody responses were monitored using ELISA. Immunoplates (Nunc VWR Scientific, Bridgeport, NJ) were coated at $4^{\circ} \mathrm{C}$ overnight with $100 \mathrm{ng}$ of the following antigens, in house monovalent enzyme-linked immunosorbent assay (ELISA, the plate antigens were prepared by sonicating the Pasteurella multocida type A strain. Whole cell lysates were placed in borate buffer $(\mathrm{pH}$ 9.5) 1:1. The plates were washed with $50 \mu \mathrm{l}$ of $0.01 \mathrm{M}$ PBS containing $0.05 \%$ Tween $20(\mathrm{pH}$ 7.2), followed by the addition of $200 \mu \mathrm{l}$ of blocking buffer (PBS containing 1\% bovine serum albumin). Samples $(50 \mu \mathrm{l})$ were then incubated at temperature $\sim 20 \mathrm{C}$ for $30 \mathrm{~min}$. After the plates were washed, $50 \mu \mathrm{l}$ of antisera serially diluted with blocking buffer was added, and the plates were incubated at $\sim 20 \mathrm{C}$ for 30 min. After a further washing, $50 \mu \mathrm{l}$ of 1:5000 diluted rabbit anti-pig immunoglobulin G conjugated to horseradish peroxidase (Sigma Aldrich Chemistry Mexico: catalogue: A5670) was added, and the plates were incubated $\sim 20 \mathrm{C}$ for $1 \mathrm{~h}$. For color development, $100 \mathrm{ml}$ of 3, 39, 5, 59-tetramethylbenzidine substrate was added, and the plates were incubated for $30 \mathrm{~min}$. Then, $100 \mathrm{ml}$ of a $0.25 \%$ solution of hydrofluoric acid was added to stop the reaction. Absorbance was read at a wavelength of $630 \mathrm{~nm}$ with an ELISA reader (Multiskan EX type 355; Thermo Fisher Scientific (Shanghai) Instrument Co. Ltd). The positive/negative ratio method of analysis was used to determine the antibody titer of treated pigs. After a log transformation of the ELISA titer, a linear relationship was confirmed between the ELISA titer and the positive/negative ratio [20] [21] [22].

\subsection{Trial Registration}

The manuscript does not contain clinical studies or patient data; the samples used in this study were voluntarily provided by veterinarians and pig farmers.

\section{Results}

\subsection{Bacterial Strain}

Bacterial Strain. The viability of Pasteurella multocida in the dry emulsion was confirmed by the $\mathrm{CFU} / \mathrm{ml}$. In only two cases, the CFU/ml decreased from $10^{8}$ to $10^{6}$. There was no significant difference among the batches and bacterial suspensions with the same concentration. The dry emulsion and the preparation process do not affect the viability of Pasteurella multocida.

\subsection{Disperse-Adsorbed System}

Disperse-Adsorbed System. The values obtained for bioadhesive force were 5045 \pm 85 dynes $/ \mathrm{cm}^{2}$ and $4780 \pm 76$ dynes $/ \mathrm{cm}^{2}$ for duodenal and jejunal mucosa, re- 
spectively, the release profile of Pasteurella multocida from the dry emulsion where CFU/g correspond to the accumulative bacteria released by gram of the system. Two steps can be observed, first a burst release until $5 \mathrm{~h}$ followed by a slow constant release until $120 \mathrm{~h}$.

\subsection{Experimental Design}

Animals. After the experiment, the animals showed neither temperature nor clinical signs.

\subsection{Scanning Electron Microscopy (SEM)}

Some samples like examples of the SEM revealed that the system is an organized association of particles, and water globules of sizes between $2.5-5.0 \mu \mathrm{m}$. The bacteria were apparently intact and localized adjacent to the particles in the aqueous domain. The rheological behavior of the dispersion is similar to that observed for cosmetic and pharmaceutical pastes. The bioadhesion study revealed areas of intestine completely covered by the emulsion. The marker was located mainly on the duodenum and jejunum. Apparently, the structure of the villi in the ileum did not allow for the adherence of the dry emulsion. On the duodenum, the system was found as bridges between villi (Figure 1) and at the bottom of the villi (Figure 2). In the case of the jejunum, the emulsion adopted the form of a sheet that covered important areas of the intestine. In this region, the marker can be clearly distinguished together with bacterial bodies (Figure 3). This interaction between the dry emulsion and mucosa was confirmed by the measurements of bioadhesive force.

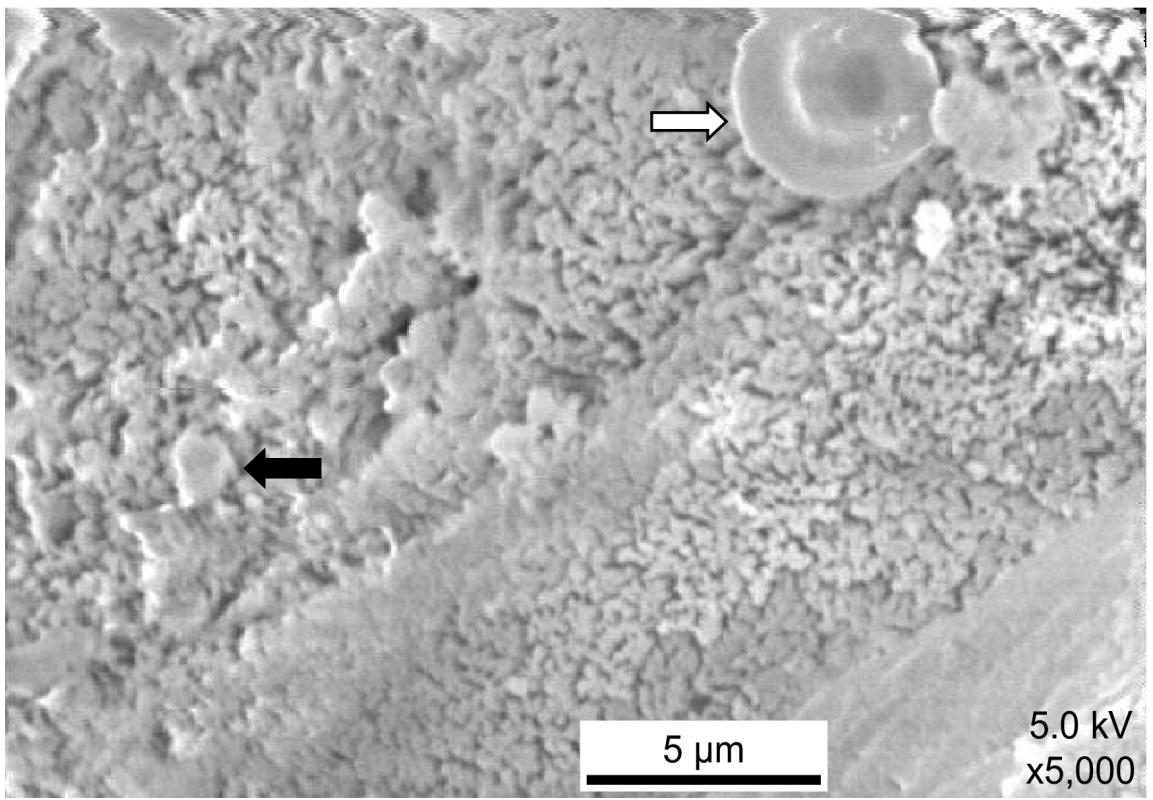

Figure 1. Scanning electronic microscopy micrograph of emulsion at the surface of the intestinal duodenum mucous membrane. The silver flakes (black arrow) and a red blood cell can be seen (white arrow). 


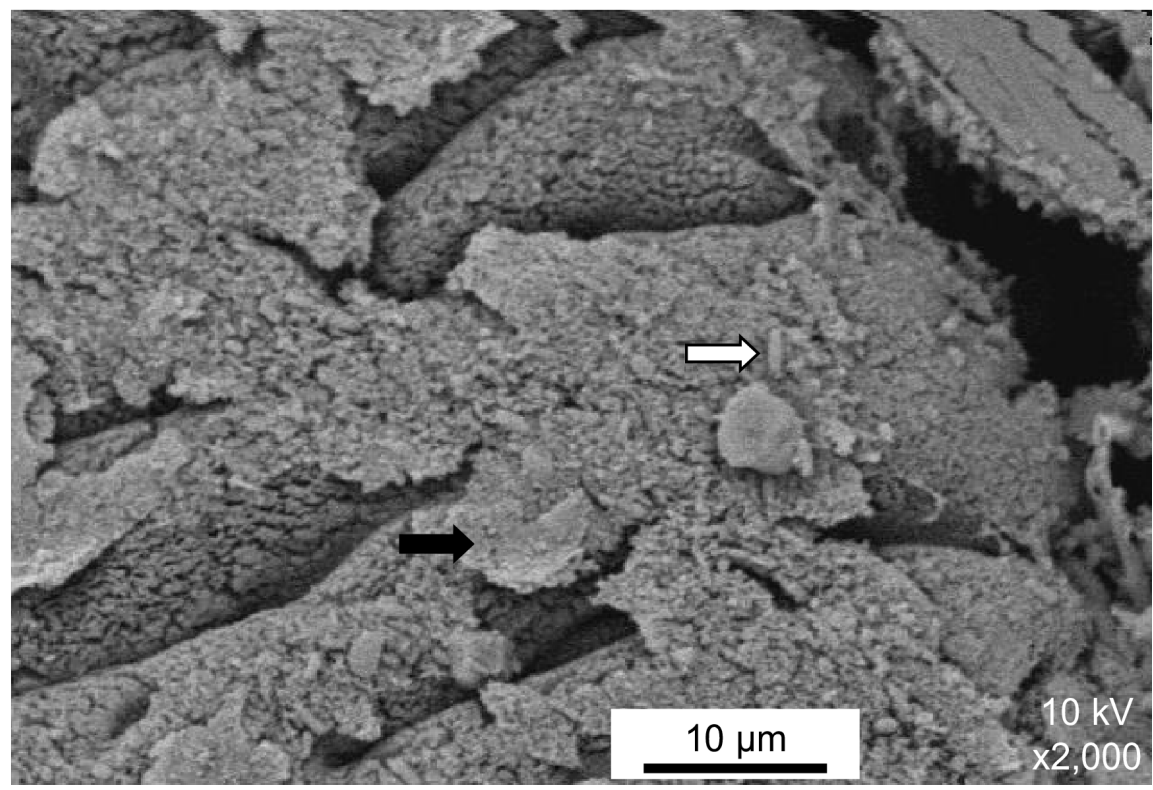

Figure 2. Scanning electronic microscopy micrograph of a sheet of the emulsion covers the surface of a villus. A silver flake (black arrow) and several bacterial bodies are visible (white arrows).

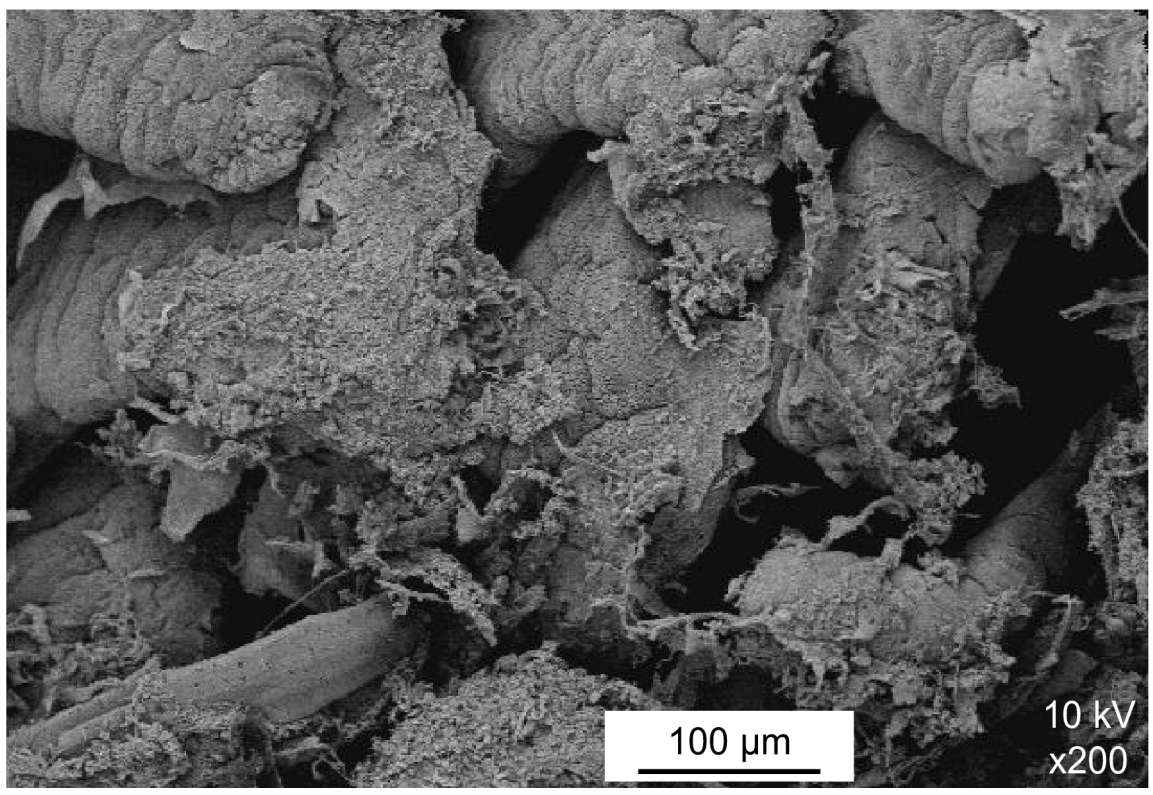

Figure 3. Scanning electronic microscopy micrograph of panoramic view of another area of the sample where both the biogel and the emulsion have been preserved.

\subsection{Serology}

The ELISA technique was used to monitor the mean antibody titer of treated pigs over the 2-week period, and a classic primary response curve occurred when the titer was plotted against time. The sorbent alone did not detect an antibody response, in the sorbent and Pasteurella multocida group, antibodies were detected at 7 days and a double response at 15 days (Table 1 ). 
Table 1. Antibodies were detected at 7 days and 15 days, in the three study groups, by means of a home ELISA test.

\begin{tabular}{cccc}
\hline Groups & 1 day & 7 days & 15 days \\
\hline A: Control & 0 & 0 & 0 \\
B: Sorbent Only & 0 & 0 & 0 \\
C: Pasteurella multocida + Sorbent & 0 & 0.15 & 0.30
\end{tabular}

\section{Discussion}

Scanning electron micrographs revealed that the system is an organized association of particles described by a tetrakaidecahedral geometry. The bacteria were apparently intact and localized adjacent to the particles in the aqueous domain. A similar structure has been reported by Berthod et al. [12] for dry absorbed emulsions containing sodium salicylate. The not viability of Pasteurella multocida in the dry emulsion was confirmed by CFU/ml. The bioadhesion study revealed areas of intestine completely covered by the emulsion. The marker was located mainly on the duodenum and jejunum. Apparently, the structure of the villi in the ileum did not allow for the adherence of the dry emulsion. The values obtained for bioadhesion force were $5045 \pm 85$ dynes $/ \mathrm{cm}^{2}$ and $4780 \pm 76$ dynes $/ \mathrm{cm}^{2}$ for duodenal and jejunal mucosa, respectively. These values are similar to those obtained by Quintanar et al. [13] for polymers exhibiting good bioadhesivity. On the duodenum, the system was found as bridges between villi and at the bottom of the villi. In the case of the jejunum, the emulsion adopted the form of a sheet that covered important areas of the intestine. In this region, the marker can be clearly distinguished together with the bacterial bodies. This interaction between the dry emulsion and mucosa was confirmed by the measurements of bioadhesive force.

This strong adhesion to mucosa suggests that the system did not elute during the adhesion test and could stay adhered to the surface of mucosa for approximations estimated in this study, therefore increasing bacterial exposure at this level. The system showed a narrow relationship with the duodenal mucosa after the elution process. On the other hand, the delivery tests showed a linear pattern of the curve within 5 hours, characterized by a quick discharge of not viable Pasteurella multocida followed by a change in the slope of the curve after 5 hours of release and a delayed effect in deliverance that stays constant and prolonged until 120 hours. It is possible that after approximately 5 hours of deliverance, the CFU observed correspond to a summation of the development of bacteria that had been delivered because the support media had all necessary nutrients for growing Pasteurella multocida, and there were remaining bacteria that were still delivered from the system. These data suggest that the dry emulsion is capable to retain a percentage of bacteria $(\approx 65 \%)$ and is also capable of prolonging their release and keep its viability under these conditions. The ELISA technique was used to monitor the mean antibody titer of treated, and a classic 
primary response curve occurred when the titer was plotted against time.

There were three aims of this study: 1) the first was to probe the viability of the bacteria in the dry emulsion; 2) the second was the possibility of obtaining a system that can potentially protect the bacteria and ensure controlled release of the antigen; and 3) the third aim was to prove the capacity of the dry emulsion to protect the bacteria and to provoke antigenic responses. Dry emulsions are proposed as a new oral carrier for veterinary vaccines. The system behaved as a new carrier capable of maintaining the viability of the bacteria. The dry emulsion showed excellent bioadhesive properties on the duodenal and jejunal regions in vitro as expressed by the retention properties and adhesion force. The release of Pasteurella multocida from the dry emulsion revealed a rapid release followed by sustained bacterial populations. Thus, the dry-emulsion has good potential to protect biological materials without affecting their integrity, it has a good bioadhesion and controlled release behavior which can have important implications with the immune response by oral route. Moreover, we plan to focus on evaluating the system as an oral carrier for other types of veterinary immunogens. This work proposes a practical approach to deliver immunogens to pigs' guts. This line of research can improve the way that swine veterinarians/practitioners and swine producers immunize the herds. This preliminary study where few animals were used and the short time of the experiment did not allow observing lung lesions.

\section{Conclusion}

In this article, it was showed that the dry emulsion can be a new strategy to protect biological materials such as bacteria in dispersion. This adsorbed-dispersed system has good bioadhesivity and controlled release properties which can have important implications in the development of immunogens by oral route for veterinary vaccines. Further studies are now conducting to evaluate the dry emulsions with other immunizing agents and for other veterinary administration routes.

\section{Author Contributions}

DQG performed the experiments, designed the study; EA performed the experiments; METO analyzed the data; SG TEM study; ACC and SEME designed the study and performed the experiments, analyzed the data, and wrote the manuscript.

\section{Funding and Acknowledgments}

Grant for UNAM-FESC PIAPI2032.

\section{Conflicts of Interest}

The authors declare no conflicts of interest regarding the publication of this paper. 


\section{References}

[1] Lehner, T., Bergmeier, L., Wang, Y.F., Tao, L. and Mitchell, E. (1999) A Rational Basis for Mucosal Vaccination against HIV Infection. Immunological Reviews, 170, 183-196. https://doi.org/10.1111/j.1600-065X.1999.tb01338.x

[2] Sedgmen, B.J., Lofthouse, S.A., Scheerlinck, J.-P.Y. and Meeusen, E.N.T. (2002) Cellular and Molecular Characterisation of the Ovine Rectal Mucosal Environment. Veterinary Immunology and Immunopathology, 86, 215-220. https://doi.org/10.1016/S0165-2427(02)00011-9

[3] Williams, P.P., Hall, M.R. and Rimler, R.B. (1990) Host Response to Pasteurella multocida Turbinate Atrophy Toxin in Swine. Canadian Journal of Veterinary Research, 54, 157-163.

[4] Pettit, R.K., Rimler, R.B. and Ackermann, M.R. (1993) Protection of Pasteurella multocida Dermonecrotic Toxin-Challenged Rats by Toxoid-Induced Antibody. Veterinary Microbiology, 34, 167-173. https://doi.org/10.1016/0378-1135(93)90170-C

[5] Pijoan, C., Lastra, A., Ramirez, C. and Leman, A. (1984) Isolation of Toxigenic Strains of Pasteurella multocida from Lungs of Pneumonic Swine. Journal of the American Veterinary Medical Association, 185, 522-523.

[6] Ciprián, A., Pijoan, C., Sánchez, T., Camacho, J., Tortora, J., Colmenares, G., López-Revilla, R. and Garza, M. (1988) Mycoplasma hyopneumoniae Increases the Susceptibility of Pigs to Experimental Pasteurella multocida Pneumonia. Canadian Journal of Veterinary Research, 52, 434-438.

[7] Register, K.B. and Brockmeier, S.L. (2019) Pasteurellosis. In: Zimmerman, J.J., Karriker, L.A., Ramirez, A., Schwartz, K.J., Stevenson, G.W. and Zhang, J.Q., Eds., Disease of Swine, 11th Edition, John Wiley \& Sons, Inc., Hoboken, 884-897. https://doi.org/10.1002/9781119350927.ch57

[8] Torche, A.M., Le Dimna, M., Le Corre, P., Mesplede, A., Le Gal, S., Cariolet, R. and Le Potier, M.F. (2006) Immune Responses after Local Administration of IgY Loaded-PLGA Microspheres in Gut-Associated Lymphoid Tissue in Pigs. Veterinary Immunology and Immunopathology, 109, 209-217.

https://doi.org/10.1016/j.vetimm.2005.08.016

[9] Bailey, M., Haverson, K. and Stokes, C. (1996) Immunological Functions of the Intestinal Lamina Propria. In: Tumbleson, M.E. and Schook, L., Eds., Swine in Biomedical Research, Plenum Press, New York, 267-275.

[10] Makala, L.H.C., Haverson, K., Stokes, C., Bailey, M. and Bland, P. (1998) Isolation and Characterisation of Pig Peyer's Patch Dendritic Cells. Veterinary Immunology and Immunopathology, 61, 67-81. https://doi.org/10.1016/S0165-2427(97)00125-6

[11] Andersen, J., Takamatsu, H., Oura, C., Brookes, S., Pullen, L. and Parkhouse, R. (1999) Systematic Characterization of Porcine Ileal Peyer's Patch, I. Apoptosis-Sensitive Immature B Cells Are the Predominant Cell Type. Immunology, 98, 612-621. https://doi.org/10.1046/j.1365-2567.1999.00922.x

[12] Berthod, A., Rollet, M. and Farah, N. (1988) Dry Adsorbed Emulsions: An Oral Sustained Drug Delivery System. Journal of Pharmaceutical Sciences, 77, 216-221. https://doi.org/10.1002/jps.2600770307

[13] Quintanar G.D., Villalobos G.R., Alvarez C.E. and Cornejo B.J.M. (2001) In Vitro Evaluation of Bioadhesive Properties of Hydrophobic Polybasic Gels Containing $N, N$-Dimethylaminoethyl Methacrylate-Co-Methyl Methacrylate. Biomaterials, 22, 957-961. https://doi.org/10.1016/S0142-9612(00)00260-X 
[14] Božić, F., Lacković, G., Stokes, C.R. and Valpotić, I. (2002) Recruitment of Intestinal

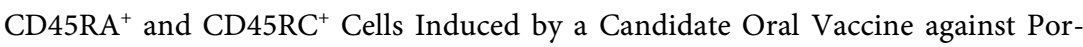
cine Post-Weaning Colibacillosis. Veterinary Immunology and Immunopathology, 86, 137-146. https://doi.org/10.1016/S0165-2427(02)00033-8

[15] Carter, G. and Rundell, S. (1975) Identification of Type A Strains of P multocida Using Staphylococcal Hyaluronidase. Vet Record, 96, 343-343. https://doi.org/10.1136/vr.96.15.343

[16] Zhang, J.S., Wang, M.F., Zhou, N.N., Shen, Y.J. and Li, Y.F. (2018) Evaluation of Carbopol as an Adjuvant on the Effectiveness of Progressive Atrophic Rhinitis Vaccine. Vaccine, 36, 4477-4484. https://doi.org/10.1016/j.vaccine.2018.06.023

[17] Farah, N., Bouzon, J., Rollet, M., Taverdet, J.L. and Vergnaud, J.M. (1987) "Dry Emulsion"-A Sustained Release Form: Modelling of Drug Transfers in Liquids. International Journal of Pharmaceutics, 36, 81-88. https://doi.org/10.1016/0378-5173(87)90240-7

[18] Rao, K.V.R. and Buri, P. (1989) A Novel in Situ Method to Test Polymers and Coated Microparticles for Bioadhesion. International Journal of Pharmaceutics, 52, 265-270. https://doi.org/10.1016/0378-5173(89)90229-9

[19] Vea-Barragana, A.C., Bucio, E., Quintanar-Guerrero, D., Zambrano-Zaragoza, M.L., Meléndez-López, S.G., Serrano-Medina, A. and Cornejo-Bravo, J.M. (2019) Poly(Acrylic Acid)-Grafted Hydrophobic Weak Acid Gels as Mucoadhesives for Controlled Drug Release. Radiation Physics and Chemistry, 164, Article ID: 108372. https://doi.org/10.1016/j.radphyschem.2019.108372

[20] Briggs, D.J. and Skeeles, J.K. (1984) An Enzyme-Linked Immunosorbent Assay for Detecting Antibodies to Pasteurella multocida in Chickens. Avian Diseases, 28, 208-215. https://doi.org/10.2307/1590143

[21] Roier, S., Fenninger, J.C., Leitner, D.R., Rechberger, G.N., Reidl, J. and Schild, S. (2013) Immunogenicity of Pasteurella multocida and Mannheimia Haemolytica Outer Membrane Vesicles. International Journal of Medical Microbiology, 303, 247-256. https://doi.org/10.1016/j.ijmm.2013.05.001

[22] Bozzola, J.J. and Russell, L.D. (1999) Electrón Microscopy. Jones and Bartlett Publishers, Sudbury, Masssachussetts.

[23] Luo, Y., Glisson, J.R., Jackwood, M.W., Hancock, R., Bains, M., Cheng, I. and Wang, C. (1997) Cloning and Characterization of the Major Outer Membrane Protein Gene (ompH) of Pasteurella multocida X-73. Journal of Bacteriology, 179, 7856-7864. https://doi.org/10.1128/JB.179.24.7856-7864.1997 